\title{
Long-term results of liver transplantation for polycystic liver disease: Single-center experience in China
}

\author{
FAN DING ${ }^{1,2^{*}}$, HUI TANG ${ }^{1,2^{*}}$, HUI ZHAO ${ }^{1,2}$, XIAO FENG $^{1,2}$, YANG YANG $^{1,2}$, \\ GUI-HUA CHEN ${ }^{1,2}$, WEN-JIE CHEN $^{3}$ and CHI XU ${ }^{1,2}$ \\ ${ }^{1}$ Department of Hepatic Surgery and Liver Transplantation Center, The Third Affiliated Hospital, \\ Sun Yat-Sen University, Guangzhou, Guangdong 510630; ${ }^{2}$ Organ Transplantation Institute, \\ Sun Yat-Sen University, Guangzhou, Guangdong 510080; ${ }^{3}$ Department of Biological Treatment Center, \\ The Third Affiliated Hospital, Sun Yat-Sen University, Guangzhou, Guangdong 510630, P.R. China
}

Received July 29, 2018; Accepted February 15, 2019

DOI: $10.3892 /$ etm.2019.7449

\begin{abstract}
The aim of the present study was to explore the indications for and safety of orthotopic liver transplantation for polycystic liver disease (PLD). Orthotopic liver transplantation in 11 patients with PLD between May 2004 and September 2013 was retrospectively analyzed. Patient epidemiological, clinical and follow-up data were collected. The survival rate was calculated using the Kaplan-Meier method. Over the 10-year period, 11 patients received orthotopic liver transplantation $(\mathrm{n}=9)$ and combined liver-kidney transplantation $(\mathrm{n}=2)$ for PLD. The recipients' median age was 56 years [(interquartile range (IQR), 52-57 years], and 7 of the patients (63.6\%) were classified as having Gigot type II PLD and $4(36.4 \%)$ as having Gigot type III. A total of $8(72.7 \%)$ patients had a severely decreased quality of life (Eastern Cooperative Oncology Group performance status score, $\geq 3$ ). Only 3 cases $(27.3 \%)$ were of Class C stage. The mean hospitalization duration was $45.4 \pm 15.3$ days and the mean length of stay at the intensive care unit was $4.1 \pm 1.9$ days. The peri-operative mortality was $18.2 \%$ and the morbidity was $54.5 \%$. The median follow-up period was 111 months (IQR, 33-132 months). A total of 2 patients died of severe complications after combined liver-kidney transplantation.
\end{abstract}

Correspondence to: Professor Chi Xu, Department of Hepatic Surgery and Liver Transplantation Center, The Third Affiliated Hospital, Sun Yat-Sen University, 600 Tianhe Road, Guangzhou, Guangdong 510630, P.R. China

E-mail: xuchisysu@163.com

Professor Wen-Jie Chen, Department of Biological Treatment Center, The Third Affiliated Hospital, Sun Yat-Sen University, 600 Tianhe Road, Guangzhou, Guangdong 510630, P.R. China E-mail: chenwenjiesysu@163.com

${ }^{*}$ Contributed equally

Key words: polycystic liver disease, autosomal dominant polycystic kidney disease, liver transplantation, hepatitis B
Furthermore, 1 patient died of ischemia cholangitis during the follow-up period. The actuarial 1-, 5- and 10-year survival rate during the follow-up period was $81.8,81.8$ and $65.5 \%$, respectively. The mean physical component summary score was $87.1 \pm 6.9$ and the mean mental component summary score was $81.5 \pm 6.4$. In conclusion, liver transplantation is the only curative procedure for PLD, and the present study indicated that it is relatively and safe and leads to good long-term prognosis and high quality of life. Based on our experience and results, liver transplantation is a primary option for cases of PLD with progressive or advanced symptomatic disease where previous other forms of therapy to palliate symptoms have been insufficient.

\section{Introduction}

Polycystic liver disease (PLD) is a group of genetic disorders, which may either only be present in the liver (isolated PLD), involve the kidney [autosomal-dominant polycystic kidney disease (ADPKD)], or, as a rare occurrence, be complicated with congenital hepatic fibrosis (CHF) (1). Regardless of the distinct genetic mutation, the natural progression is mostly similar between different types. Most patients with PLD are asymptomatic and only a minority of patients is symptomatic with persistently normal liver functions (2). The expansion of liver cysts causes extensive hepatomegaly and serious abdominal symptoms. Current medical treatments have indicated potential therapeutic effects, but further research is still required $(3,4)$. Liver transplantation remains the only definitive curative procedure. Other surgical interventions may relieve symptoms by reducing liver cysts. These palliative disease-directed interventions are associated with high rates of recurrence, morbidity and mortality, which may eventually complicate liver transplantation (5). However, liver transplantation remains controversial due to the shortage of donors, as well as high morbidity and mortality. The present study revealed that appropriately selected patients with extensive hepatic involvement or HBV-associated decompensated cirrhosis complicated with PLD treated by liver transplantation had an excellent long-term prognosis compared with those subjects receiving other surgical treatments. The present 
study aimed to explore the indications for and safety of liver transplantation for PLD.

\section{Materials and methods}

Patients. A retrospective analysis of 11 patients with PLD who were diagnosed at the Third Affiliated Hospital of Sun Yat-Sen University (Guangzhou, China) between May 2004 and September 2013 was performed. The study was supervised and approved by the Ethics Committee of the Third Affiliated Hospital, Sun Yat-Sen University [Guangzhou, China; no. (2018)02-006-011]. Written informed consent was obtained from all of the patients or the patients' first-degree relatives.

Examination. The diagnosis of PLD was defined as the presence of $>20$ liver cysts revealed by ultrasonography, computed tomography (CT) scan or magnetic resonance imaging (MRI) scan (6). Furthermore, if PLD presented as the extrarenal progression in ADPKD, $\geq 4$ liver cysts were regarded as sufficient for diagnosis (7). The severity and classification of PLD were defined based on the Gigot criteria (8). The routine examinations, including electrocardiography, chest radiograph or chest $\mathrm{CT}$ and blood test, were performed for pre-operative assessment. The Child-Pugh scores $(9,10)$, as well as the score of the Short-Form (36) Health Survey (SF-36) questionnaire, the Eastern Cooperative Oncology Group (ECOG) performance status (11) and the Clavien-Dindo classification (12) were determined as the risk factors of orthotopic liver transplantation (OLT) and the short- and long-term prognosis.

Treatment and follow-up. The 11 patients underwent modified piggyback OLT or combined liver-kidney transplantation (CLKTx) according to the degree of renal dysfunction and the regional anatomical structure during surgery. A total of six patients (Patients 2, 5, 7 and 9-11) were indicated to have a severely decreased quality of life (ECOG $\geq 3$ ). End-stage liver disease progressed from isolated PLD and hepatitis B virus (HBV)-associated cirrhosis were indications in the other five patients. Of note, Patients 10 and 11 underwent CLKTx due to complication with renal dysfunction. The data of the prior surgical history, warm ischemia time, cold ischemia time, time of anhepatic phase, volume of ascites, type of surgery, biochemical or radiologic examinations, post-operative complications and immunosuppressive treatment were recorded. Patients were followed up until January 2018.

Statistical analysis. The survival of patients was assessed with a Kaplan-Meier analysis using GraphPad Prism 6.0 software (version 6.01; GraphPad Software, Inc. San Diego, CA, USA). Measurement data were expressed as mean \pm standard deviation or median [interquartile range (IQR), $\mathrm{Q}_{1}-\mathrm{Q}_{3}$ ].

\section{Results}

Patients characteristics. A total of 11 recipients (6 males and 5 females) underwent modified piggyback OLT $(n=9)$ or CLKTx $(n=2)$ for PLD between May 2004 and September 2013 at the Transplantation Center of the Third Affiliated Hospital of Sun Yat-Sen University (Guangzhou, China), accounting for $1.09 \%$ of all OLTs performed at our center. Recipient characteristics are summarized in Table I. The recipients' median age was 56 years (IQR, 52-57 years). All recipients underwent pre-operative $\mathrm{CT}$ scan or MRI scan to confirm the diagnosis (6 cases of isolated PLD and 5 of ADPKD). In fact, among the PLD subgroup, only 1 patient (Patient 7) was diagnosed with isolated PLD, while the other 5 patients all had a history of hepatitis B, which progressed to hepatic failure. The hepatitis $\mathrm{B}$ of all of those 5 patients was under effective control by anti-HBV drugs (HBs antigen was negative and HBV-DNA quantification <100 copies/ml). Abdominal CT scan revealed that 7 patients (63.6\%) had Gigot type II PLD and 4 (36.4\%) had Gigot type III PLD; representative CT scans are presented in Fig. 1. A total of eight patients suffered from massive hepatomegaly with abdominal pain, discomfort, shortness of breath and limited daily activities ( 8 had an ECOG score of $\geq 3$ and 3 had an ECOG score of 2). There were 8 cases $(72.7 \%$ ) of Child-Pugh Class B, and 3 cases $(27.3 \%)$ of Child-Pugh Class C. A history of abdominal surgery was present in 5 patients. A total of 4 patients underwent palliative surgical intervention for PLD. Specifically, Patient 4 underwent segmental hepatectomy, Patient 7 underwent aspiration-sclerotherapy combined with fenestration, Patient 9 underwent aspiration-sclerotherapy and Patient 10 underwent aspiration. Patient 1 underwent splenectomy due to hypersplenism associated with chronic hepatitis B.

Peri-operative period. During the liver transplantation period, the median ascites volume was 1,000 $\mathrm{ml}$ (IQR, 600-4,000 ml), the mean warm ischemia time was $4.36 \pm 1.74 \mathrm{~min}$, the mean cold ischemia time was $7.73 \pm 2.53 \mathrm{~h}$, and the anhepatic phase time was $43.91 \pm 12.53 \mathrm{~min}$; detailed data are presented in Tables II and III. In Patient 2, the difficult explantation of the recipient liver resulted in massive hemorrhage and increased operation time during the separation procedure of the hepatic ligaments. The mean post-operative hospitalization duration was $45.4 \pm 15.3$ days and the mean length of stay at the intensive care unit was $4.1 \pm 1.9$ days. Methylprednisolone combined with Tacrolimus was used for basic immunosuppressive management. Patient 4 exhibited an improved therapeutic response upon addition of Rapamycin. Mycophenolate mofetil was added due to the high level of serum creatinine in Patients 6 and 7. According to the Clavien-Dindo classification system, six patients were classified as grade II based on total parenteral nutrition post-transplantation. In particular, Patient 9 experienced early acute rejection after OLT, which was effectively managed by increasing the Tacrolimus dose and providing steroid hormone aggressive therapy. A total of 2 patients were classified to grade IIIa for intrahepatic or extrahepatic bile duct stricture. The condition in Patient 1 was temporarily relieved by endoscopic retrograde cholangiopancreatography and Patient 6 was cured by percutaneous transhepatic cholangiodrainage combined with balloon dilatation. Patient 5, who was classified as grade IVa, was subjected to re-transplantation due to hepatic artery stricture at 45 days after the first OLT. Patients 10 and 11 were classified as grade V due to death within 1 month post-CLKTx. Patient 10 died of multiple organ dysfunction syndrome (MODS) induced by fungal pneumonia and Patient 11 died of primary non-function (PNF) progressed from acute kidney rejection. 
Table I. Patient characteristics.

\begin{tabular}{|c|c|c|c|c|c|c|}
\hline $\begin{array}{l}\text { Patient } \\
\text { no. }\end{array}$ & $\begin{array}{c}\text { Age } \\
\text { (years) }\end{array}$ & Sex & Diagnosis & $\begin{array}{l}\text { Child-Pugh } \\
\text { score }\end{array}$ & $\begin{array}{c}\text { ECOG } \\
\text { score }\end{array}$ & $\begin{array}{c}\text { Prior } \\
\text { procedures }\end{array}$ \\
\hline 1 & 64 & Male & Isolated PLD, hepatitis B & $\mathrm{C}$ & 3 & Splenectomy \\
\hline 2 & 49 & Female & ADPKD & $\mathrm{C}$ & 4 & \\
\hline 3 & 52 & Male & Isolated PLD, hepatitis B & $\mathrm{B}$ & 2 & \\
\hline 4 & 57 & Male & Isolated PLD, hepatitis B & $\mathrm{B}$ & 2 & Segmental hepatectomy \\
\hline 5 & 47 & Male & ADPKD & $\mathrm{B}$ & 3 & \\
\hline 6 & 54 & Male & Isolated PLD, hepatitis B & $\mathrm{B}$ & 2 & \\
\hline 7 & 57 & Male & Isolated PLD & $\mathrm{B}$ & 3 & Aspiration-sclerotherapy; fenestration \\
\hline 8 & 68 & Female & Isolated PLD, hepatitis B & $\mathrm{B}$ & 3 & \\
\hline 9 & 56 & Female & ADPKD & $\mathrm{C}$ & 3 & Aspiration-sclerotherapy \\
\hline 10 & 56 & Female & ADPKD & $\mathrm{B}$ & 4 & Aspiration \\
\hline 11 & 57 & Female & ADPKD & B & 3 & \\
\hline
\end{tabular}

PLD, polycystic liver disease; ADPKD, autosomal dominant polycystic kidney disease; ECOG, Eastern Cooperative Oncology Group performance status.
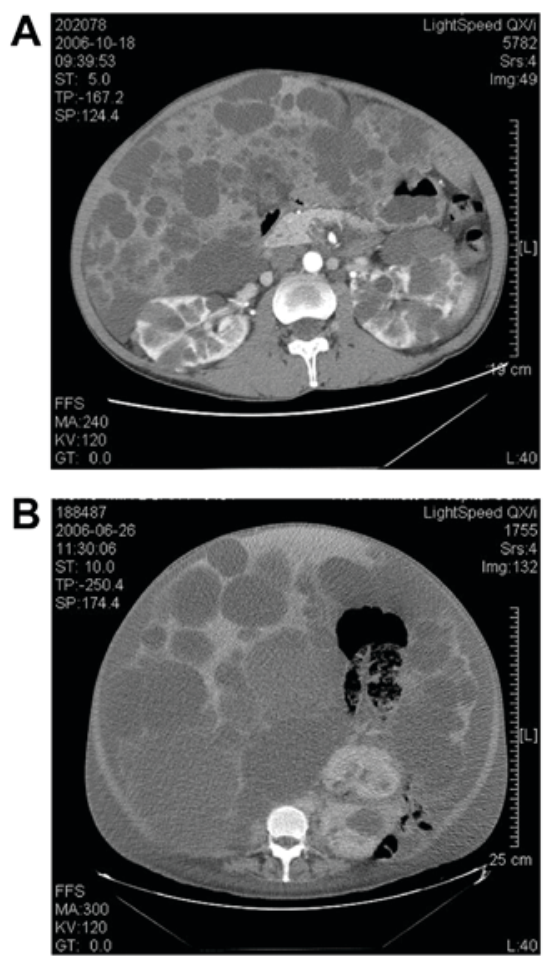

Figure 1. Gigot type II-III polycystic liver disease. Representative computed tomography images of (A) the classical Gigot type II polycystic liver with diffuse multiple medium-sized cysts (Patient 2) and (B) the classical Gigot type III polycystic liver with massive diffuse small or medium sized cysts (Patient 5).

Survival following liver transplantation. All patients received ABO blood type-compatible and whole-cadaver graft transplantation. The mortality rate was $18.2 \%(\mathrm{n}=2)$ and the morbidity rate was $54.5 \%(\mathrm{n}=6)$ during the hospitalization period. These included 2 cases of biliary complications, 1 case of hepatic artery strictures that received re-transplantation at 45 days post-OLT and 1 case of acute liver rejection. Of note, there was 1 case of fungal pneumonia (Patient 10), who died due to MODS at 12 days post-CLKTx, while another case (Patient 11) died of PNF at 34 days post-CLKTx. The median follow-up period was 111 months (IQR, 33-132 months). Only Patient 1 died due to ischemia cholangitis at 124 months post-OLT. According to the SF-36 questionnaire, the mean physical component summary (PCS) score was $87.1 \pm 6.9$ and the mean mental component summary (MCS) score was $81.5 \pm 6.4$, which indicated that the surviving patients were capable of normal activity, with only a few symptoms or signs of disease (Table III). The actuarial 1-, 5- and 10-year patient survival rates during the follow-up period were $81.8,81.8$ and $65.5 \%$, respectively (Fig. 2).

\section{Discussion}

PLD is a rare congenital disorder, which is pathologically developed from isolated hepatic cysts (isolated PLD), advanced secondary to kidney cysts (ADPKD), Caroli's disease or CHF. Regarding the genetic diagnosis of primary PLD, mutations in three genes, protein kinase substrate $80 \mathrm{~K}-\mathrm{H}$ (PRKCSH) $(13,14)$, SEC63 (15) and low-density lipoprotein receptor-related protein 5 (16), are known to be associated with the pathology, with PRKCSH being the most frequent $(\sim 15 \%)$ (17). As pathogenic genes for ADPKD, PKD1 ( 80-85\% of cases) and PKD2 ( 10-15\% of cases) have been identified (18). In addition, mutations in PKHD1 are causative for Caroli's disease as well as CHF $(19,20)$. The diagnostic criterion for primary PLD is usually defined as the presence of $>20$ cysts by ultrasonography, CT or MRI scan, particularly CT or MRI scan. For the diagnosis of ADPKD, $>4$ liver cysts are sufficient if the patient's family background includes inherited autosomal dominant isolated polycystic liver $(6,7)$.

Although isolated PLD and ADPKD are genetically distinct, the clinical progression is largely similar. Most patients are initially asymptomatic (21). However, with the continuous expansion of liver cysts, a small number of patients develops massive hepatomegaly-associated abdominal symptoms, including pain, anorexia, dyspnea and 
Table II. Peri-operative characteristics.

\begin{tabular}{llrrrrrr}
\hline $\begin{array}{l}\text { Patient } \\
\text { no. }\end{array}$ & \multicolumn{1}{c}{ Procedure } & $\begin{array}{c}\text { Ascites } \\
(\mathrm{ml})\end{array}$ & $\begin{array}{c}\text { WIT } \\
(\mathrm{min})\end{array}$ & $\begin{array}{c}\text { CIT } \\
(\mathrm{h})\end{array}$ & $\begin{array}{c}\text { Anhepatic } \\
\text { phase (min) }\end{array}$ & $\begin{array}{c}\text { Clavien-Dindo } \\
\text { classification }\end{array}$ & $\begin{array}{c}\text { Immunosuppressive } \\
\text { regimen }\end{array}$ \\
\hline 1 & Modified piggyback OLT & 3,000 & 4 & 7 & 45 & IIIa & MP + Tacrolimus \\
2 & Modified piggyback OLT & 6,000 & 4 & 12 & 48 & II & MP + Tacrolimus \\
3 & Modified piggyback OLT & 2,000 & 3 & 5 & 45 & II & MP + Tacrolimus \\
4 & Modified piggyback OLT & 700 & 3 & 9 & 50 & II & MP + Tacrolimus + Rapamycin \\
5 & Modified piggyback OLT & 1,000 & 3 & 10 & 30 & IVa & MP + Tacrolimus \\
6 & Modified piggyback OLT & 600 & 5 & 11 & 30 & IIIa & MP + Tacrolimus + MMF \\
7 & Modified piggyback OLT & 900 & 5 & 7 & 70 & II & MP + Tacrolimus + MMF \\
8 & Modified piggyback OLT & 500 & 3 & 8 & 27 & II & MP + Tacrolimus \\
9 & Modified piggyback OLT & 7,000 & 9 & 4 & 55 & II & MP + Tacrolimus \\
10 & CLKTx & 4,000 & 4 & 6 & 38 & V & MP + Tacrolimus \\
11 & CLKTx & 300 & 5 & 6 & 45 & V & MP + Tacrolimus \\
\hline
\end{tabular}

OLT, orthotopic liver transplantation; CLKTx, combined liver-kidney transplantation; WIT, warm ischemia time; CIT, cold ischemia time; MP, methylprednisolone; MMF, mycophenolate mofetil.

Table III. Post-operative morbidity and mortality.

\begin{tabular}{|c|c|c|c|c|c|c|}
\hline $\begin{array}{l}\text { Patient } \\
\text { no. }\end{array}$ & $\begin{array}{c}\text { Duration of } \\
\text { hospitalization } \\
\text { (days) }\end{array}$ & $\begin{array}{c}\text { ICU } \\
\text { stay } \\
\text { (days) }\end{array}$ & Complications & Intervention & Follow-up & Cause of death \\
\hline 1 & 48 & 3 & Intrahepatic bile duct stenosis & $\mathrm{ERCP}$ & Dead (122 months) & $\begin{array}{l}\text { Ischemia } \\
\text { cholangitis }\end{array}$ \\
\hline 2 & 42 & 3 & & & Alive (137 months) & \\
\hline 3 & 43 & 3 & & & Alive (132 months) & \\
\hline 4 & 37 & 5 & & & Alive (132 months) & \\
\hline 5 & 62 & 6 & Hepatic artery strictures & Re-LTx & Alive (33 months) & \\
\hline 6 & 50 & 3 & $\begin{array}{l}\text { Common bile duct } \\
\text { stenosis }\end{array}$ & $\begin{array}{l}\text { PTCD combined balloon } \\
\text { dilatation }\end{array}$ & Alive (123 months) & \\
\hline 7 & 44 & 4 & & & Alive (111 months) & \\
\hline 8 & 59 & 3 & & & Alive (103 months) & \\
\hline 9 & 68 & 9 & Acute rejection & $\begin{array}{l}\text { Steroid hormone aggressive } \\
\text { therapy }\end{array}$ & Alive (50 months) & \\
\hline 10 & 12 & 3 & Fungal pneumonia & Anti-infective therapy & Dead (12 days) & MODS \\
\hline 11 & 34 & 3 & Acute kidney rejection & $\begin{array}{l}\text { Steroid hormone aggressive } \\
\text { therapy }\end{array}$ & Dead (34 days) & PNF \\
\hline
\end{tabular}

ERCP, endoscopic retrograde cholangiopancreatography; ICU, intensive care unit; PTCD, percutaneous transhepatic cholangiodrainage; MODS, multiple organ dysfunction syndrome; PNF, primary non-function; Re-LTx, repeated liver transplantation.

decreased mobility (22). Age (35-46 years), sex (female), exogenous estrogens and multiple pregnancies are high-risk factors for liver cyst development and progression (23-25). In general, the levels of $\gamma$-glutamyltransferase, alkaline phosphatase and carbohydrate antigen 19-9 may rise in severe PLD, while the levels of liver enzymes are normal in the majority of patients. Other complications induced by massive cysts or chronic liver disease include cyst infection, ascites, spontaneous peritonitis, hepatic venous outflow obstruction, inferior vena cava syndrome and portal vein compression, which may result in irreversible hepatic failure (26-29).

Treatments for PLD aim to reduce the volume or numbers of liver cyst-associated complications in symptomatic patients. The pharmaceutical management may be the primary intervention applied to slowly progressing patients without severe complications or to those refusing surgical procedures. Given that oral estrogens increase liver cyst progression, any estrogen therapy should be terminated as early as possible (30). Somatostatin analogue inhibits cystic fluid secretion and 


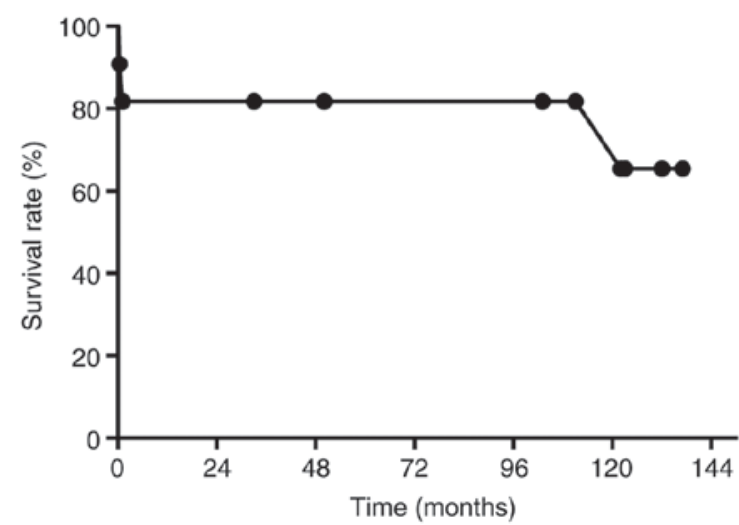

Figure 2. Patient survival rate was analyzed by Kaplan-Meier curves. The 1-, 5- and 10-year survival rates were $81.8,81.8$ and $65.5 \%$, respectively.

proliferation by reducing intracellular levels of cyclic adenosine monophosphate. According to a randomized controlled trial reported by van Hogan et al (31) and van Keimpema et al (32), $120 \mathrm{mg}$ lanreotide autogel for 6 months every 28 days or $40 \mathrm{mg}$ octreotide for 1 year every 28 days achieved an absolute decrease in liver cysts in patients with isolated PLD, while somatostatin analogue appeared to have no beneficial effect in ADPKD patients. Furthermore, certain clinical trials including mammalian target of rapamycin inhibitor or ursodeoxycholic acid management also demonstrated positive effects in reducing cyst volume in PLD $(33,34)$. Although the medical approach provides a considerable benefit in PLD patients, discontinuation of therapy would result in immediate recurrence of cyst growth (35).

At present, surgical approaches, including aspiration and sclerotherapy, fenestration and segmental hepatectomy are adapted to candidates with isolated large symptomatic cysts or Gigot type I and II PLD. These palliative disease-directed interventions are able to effectively relieve hepatomegaly-associated symptoms, but are linked to a high rate of recurrence, morbidity and mortality. Of note, the invasive procedures fail to change the natural course of the disease because symptoms usually recur due to growth of new cysts or re-growth of already treated cysts, leading to re-operation. The potential drawback of the open-abdominal procedure is the increased risk of intra-abdominal adhesions, which may complicate future liver transplantation (36).

Liver transplantation is the only curative option in patients with severe PLD (37). The indication for transplantation is extremely disabling symptoms that lead to a severely decreased quality of life. In addition, untreatable complications are indications for liver transplantation, including hepatic venous outflow obstruction, inferior vena cava syndrome, and portal vein compression or Gigot type III PLD. Following the 2008 meeting of The American Society of Transplantation, guidelines for simultaneous liver-kidney transplantation were published by Eason et al (38). These guidelines recommend that CLKTx should be performed in patients with chronic kidney disease complicated with portal hypertension or hepatorenal syndrome that have been on dialysis for $>8$ weeks and patients with a glomerular filtration rate of $\leq 30 \mathrm{ml} / \mathrm{min}$ when the patients have end-stage liver disease. Recently, Coquillard et al (39) reported that CLKTx for ADPKD was associated with better outcomes compared with patients who received CLKTx for other indications. Additionally, patients with ADPKD in the CLKTx group also had significantly better outcomes compared with patients with ADPKD undergoing liver transplant alone (39). Transplantation for PLD remains controversial due to the shortage of donors, high morbidity and mortality. However, since the first liver transplantation performed for isolated PLD by Kwok and Lewin (40) in 1988 and the first CLKTx for PLD by Starzl et al (41) in 1990, with the accumulation of surgical experience, the increased use of marginal donors and the improvement of immunosuppressant agents, transplantation has become a viable and safe treatment option for PLD and its implementation is increasing (36,42-44). As most patients have normal Model for End-stage Liver Disease (MELD) scores due to preserved liver function, the MELD exception criteria is advocated (45).

In the present study, a total of six patients with PLD (1 case of isolated PLD and 5 of ADPKD) received LTx or CLKTx due to a severely decreased quality of life (ECOG score $\geq 3$ ). Concurrent hepatic decompensation was indicated for the operation in Patients 2 and 9. Furthermore, complicated renal dysfunction was an indication for the CLKTx in Patients 10 and 11. End-stage liver disease progressed from isolated PLD and $\mathrm{HBV}$-associated cirrhosis were indications in the other five patients. Although hepatitis B was under effective control by routine treatment with anti-HBV drugs, the HBV-associated cirrhosis accelerated the progression and increased the severity of PLD to a certain extent. Based on our experience regarding OLT for end-stage liver disease associated with hepatitis B, it is recommended that PLD with hepatitis B that progressed to decompensated cirrhosis is the primary indication for transplantation; however, further clinical evidence is required to support this. The difficult and hazardous procedure was mainly attributed to the explantation of the polycystic liver, including massive enlarged liver (Patient 2), hepatic decompensation (Patient 3) and volume depletion during the reperfusion phase (Patients 10 and 11). In the present study, prior intervention did not appear to be a risk factor for transplantation. During the peri-transplantation period, the mortality and morbidity was 18.2 and $54.5 \%$, respectively. The two mortalities occurred within 1 month post-CLKTx and were due to hepatic and renal dysfunction, which tremendously increased the risk of the operation. Except for the two CLKTx cases, the morbidity and mortality in the present study was similar to that of patients with other indications for liver transplantation at our center (data not shown). At the time of writing of the manuscript, only 1 patient (Patient 1 ) died due to ischemia cholangitis at

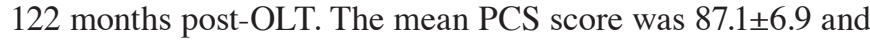
the mean MCS score was $81.5 \pm 6.4$. A total of 8 patients were alive with good graft function and high quality of life. The actuarial 1-, 5-, and 10-year patient survival rates during the follow-up period were $81.8,81.8$ and $65.5 \%$, respectively.

In conclusion, PLD is a rare congenital disorder, which is mainly diagnosed by radiological examinations. The pharmaceutical intervention or palliative disease-directed interventions may temporarily relieve hepatomegaly-associated symptoms. Due to the high recurrence rate, almost all of the cases require re-treatment. Although segmental hepatectomy is an effective procedure for patients with cysts in at least one hepatic segment, it may potentially complicate OLT in the future. Due 
to limiting factors, including the shortage of donors, as well as the higher mortality and morbidity compared with those of other surgical procedures, transplantation for a benign disease is an ethical issue. Liver transplantation is the only curative procedure for PLD, and the present study demonstrated that the intervention is relatively safe and leads to good long-term prognosis and high quality of life. Liver transplantation may be the primary therapeutic option in cases of progressive or advanced PLD where other forms of therapy to palliate symptoms were insufficient. Of note, PLD is a rare congenital disorder, only accounting for $1.09 \%$ of cases receiving OLT at our center. The small sample size was a limitation of the present single-center study and a multi-center study should be a future endeavor.

\section{Acknowledgements}

The authors would like to thank Dr Qiao-Lan Zheng from the Institute of Journal Publishing Center of the Third Affiliated Hospital, Sun Yat-Sen University (Guangzhou, China) for reviewing the statistical method of this study.

\section{Funding}

No funding received.

\section{Availability of data and materials}

All data generated or analyzed during this study are included in this published article.

\section{Author contributions}

CX and WC designed the study. GC, YY and CX performed the liver transplantations. FD, HT and XF collected the data. FD, HZ and WC analyzed the data and wrote the manuscript.

\section{Ethics approval and written informed consent}

The study was supervised and approved by the Ethics Committee of the Third Affiliated Hospital, Sun Yat-Sen University [Guangzhou, China; no. (2018)02-006-011]. Written informed consent was obtained from all of the patients or the patients' first-degree relatives.

\section{Patients' consent for publication}

Not applicable.

\section{Competing interests}

The authors declare that they have no competing interests.

\section{References}

1. Gevers TJ and Drenth JP: Diagnosis and management of polycystic liver disease. Nat Rev Gastroenterol Hepatol 10: 101-108, 2013

2. Que F, Nagorney DM, Gross JB Jr and Torres VE: Liver resection and cyst fenestration in the treatment of severe polycystic liver disease. Gastroenterology 108: 487-494, 1995.
3. Hoshino J, Ubara Y, Suwabe T, Sumida K, Hayami N, Mise K, Hiramatsu R, Hasegawa E, Yamanouchi M, Sawa N, et al: Intravascular embolization therapy in patients with enlarged polycystic liver. Am J Kidney Dis 63: 937-944, 2014.

4. Temmerman F, Ho TA, Vanslembrouck R, Coudyzer W, Billen J, Dobbels F, van Pelt J, Bammens B, Pirson Y and Nevens F: Lanreotide reduces liver volume, but might not improve muscle wasting or weight loss, in patients with symptomatic polycystic liver disease. Clin Gastroenterol Hepatol 13: 2353-2359.e2351, 2015.

5. Aussilhou B, Douflé G, Hubert C, Francoz C, Paugam C, Paradis V, Farges O, Vilgrain V, Durand F and Belghiti J: Extended liver resection for polycystic liver disease can challenge liver transplantation. Ann Surg 252: 735-743, 2010.

6. Drenth JP, Chrispijn M, Nagorney DM, Kamath PS and Torres VE: Medical and surgical treatment options for polycystic liver disease. Hepatology 52: 2223-2230, 2010.

7. Qian Q: Isolated polycystic liver disease. Adv Chronic kidney Dis 17: 181-189, 2010.

8. Gigot JF, Jadoul P, Que F, Van Beers BE, Etienne J, Horsmans Y, Collard A, Geubel A, Pringot J and Kestens PJ: Adult polycystic liver disease: Is fenestration the most adequate operation for long-term management? Ann Surg 225: 286-294, 1997.

9. Pugh RN, Murray-Lyon IM, Dawson JL, Pietroni MC and Williams R: Transection of the oesophagus for bleeding oesophageal varices. Br J Surg 60: 646-649, 1973.

10. Child CG and Turcotte JG: Surgery and portal hypertension. Major Probl Clin Surg 1: 1-85, 1964.

11. Oken MM, Creech RH, Tormey DC, Horton J, Davis TE, McFadden ET and Carbone PP: Toxicity and response criteria of the eastern cooperative oncology group. Am J Clin Oncol 5: 649-655, 1982.

12. Clavien PA, Barkun J, de Oliveira ML, Vauthey JN, Dindo D, Schulick RD, de Santibañes E, Pekolj J, Slankamenac K, Bassi C, et al: The Clavien-Dindo classification of surgical complications: Five-year experience. Ann Surg 250: 187-196, 2009.

13. Li A, Davila S, Furu L, Qian Q, Tian X, Kamath PS, King BF, Torres VE and Somlo S: Mutations in PRKCSH cause isolated autosomal dominant polycystic liver disease. Am J Hum Genet 72: 691-703, 2003.

14. Drenth JP, te Morsche RH, Smink R, Bonifacino JS and Jansen JB: Germline mutations in PRKCSH are associated with autosomal dominant polycystic liver disease. Nat Genet 33: 345-347, 2003.

15. Davila S, Furu L, Gharavi AG, Tian X, Onoe T, Qian Q, Li A, Cai Y, Kamath PS, King BF, et al: Mutations in SEC63 cause autosomal dominant polycystic liver disease. Nat Genet 36: $575-577,2004$

16. Cnossen WR, te Morsche RH, Hoischen A, Gilissen C Chrispijn M, Venselaar H, Mehdi S, Bergmann C, Veltman JA and Drenth JP: Whole-exome sequencing reveals LRP5 mutations and canonical Wnt signaling associated with hepatic cystogenesis. Proc Natl Acad Sci USA 111: 5343-5348, 2014.

17. Perugorria MJ, Masyuk TV, Marin JJ, Marzioni M, Bujanda L, LaRusso NF and Banales JM: Polycystic liver diseases: Advanced insights into the molecular mechanisms. Nat Rev Gastroenterol Hepatol 11: 750-761, 2014.

18. Rossetti S, Consugar MB, Chapman AB, Torres VE, Guay-Woodford LM, Grantham JJ, Bennett WM, Meyers CM, Walker DL, Bae K, et al: Comprehensive molecular diagnostics in autosomal dominant polycystic kidney disease. J Am Soc Nephrol 18: 2143-2160, 2007.

19. Ward CJ, Hogan MC, Rossetti S, Walker D, Sneddon T, Wang X, Kubly V, Cunningham JM, Bacallao R, Ishibashi M, et al: The gene mutated in autosomal recessive polycystic kidney disease encodes a large, receptor-like protein. Nat Genet 30: 259-269, 2002.

20. Wills ES, Roepman R and Drenth JP: Polycystic liver disease: Ductal plate malformation and the primary cilium. Trends Mol Med 20: 261-270, 2014.

21. Everson GT, Taylor MR and Doctor RB: Polycystic disease of the liver. Hepatology 40: 774-782, 2004.

22. Swenson K, Seu P, Kinkhabwala M, Maggard M, Martin P, Goss J and Busuttil R: Liver transplantation for adult polycystic liver disease. Hepatology 28: 412-415, 1998.

23. Alvaro D, Barbaro B, Franchitto A, Onori P, Glaser SS, Alpini G, Francis H, Marucci L, Sterpetti P, Ginanni-Corradini S, et al: Estrogens and insulin-like growth factor 1 modulate neoplastic cell growth in human cholangiocarcinoma. Am J Pathol 169: 877-888, 2006. 
24. Chapman AB: Cystic disease in women: Clinical characteristics and medical management. Adv Ren Replace Ther 10: 24-30, 2003.

25. Bae KT, Zhu F, Chapman AB, Torres VE, Grantham JJ, Guay-Woodford LM, Baumgarten DA, King BF Jr, Wetzel LH, Kenney PJ, et al: Magnetic resonance imaging evaluation of hepatic cysts in early autosomal-dominant polycystic kidney disease: The consortium for radiologic imaging studies of polycystic kidney disease cohort. Clin J Am Soc Nephrol 1: 64-69, 2006.

26. Rajoriya N, Tripathi D, Leithead JA, Gunson BK, Lord S, Ferguson JW and Hirschfield GM: Portal hypertension in polycystic liver disease patients does not affect wait-list or immediate post-liver transplantation outcomes. World J Gastroenterol 22: 9966-9973, 2016.

27. Barbier L, Ronot M, Aussilhou B, Cauchy F, Francoz C, Vilgrain V, Soubrane O, Paradis V and Belghiti J: Polycystic liver disease: Hepatic venous outflow obstruction lesions of the non-cystic parenchyma have major consequences. Hepatology 68 : 652-662, 2018

28. Dumont PN, Rode A, Mabrut JY, Ducerf C and Golse N Polycystic liver disease complicated by obstructive jaundice. J Visc Surg 153: 149-151, 2016.

29. Temmerman F, Dobbels F, Ho TA, Pirson Y, Vanslembrouck R, Coudyzer W, Bammens B, van Pelt J, Pirenne J and Nevens F: Development and validation of a polycystic liver disease complaint-specific assessment (POLCA). J Hepatol 61: 1143-1150, 2014.

30. Sherstha R, McKinley C, Russ P, Scherzinger A, Bronner T, Showalter R and Everson GT: Postmenopausal estrogen therapy selectively stimulates hepatic enlargement in women with autosomal dominant polycystic kidney disease. Hepatology 26: 1282-1286, 1997.

31. Hogan MC, Masyuk TV, Page LJ, Kubly VJ, Bergstralh EJ, Li X, Kim B, King BF, Glockner J, Holmes DR, et al: Randomized clinical trial of long-acting somatostatin for autosomal dominant polycystic kidney and liver disease. J Am Soc Nephrol 21: 1052-1061, 2010.

32. van Keimpema L, Nevens F, Vanslembrouck R, van Oijen MG, Hoffmann AL, Dekker HM, de Man RA and Drenth JP: Lanreotide reduces the volume of polycystic liver: A randomized, double-blind, placebo-controlled trial. Gastroenterology 137 1661-1668.e1661-1662, 2009.

33. D'Agnolo HM, Kievit W, Takkenberg RB, Riaño I, Bujanda L, Neijenhuis MK, Brunenberg EJ, Beuers U, Banales JM and Drenth JP: Ursodeoxycholic acid in advanced polycystic liver disease: A phase 2 multicenter randomized controlled trial. J Hepatol 65: 601-607, 2016.
34. Qian Q, Du H, King BF, Kumar S, Dean PG, Cosio FG and Torres VE: Sirolimus reduces polycystic liver volume in ADPKD patients. J Am Soc Nephrol 19: 631-638, 2008.

35. Chrispijn M, Nevens F, Gevers TJ, Vanslembrouck R, van Oijen MG, Coudyzer W, Hoffmann AL, Dekker HM, de Man RA, van Keimpema L and Drenth JP: The long-term outcome of patients with polycystic liver disease treated with lanreotide. Aliment Pharmacol Ther 35: 266-274, 2012.

36. Baber JT, Hiatt JR, Busuttil RW and Agopian VG: A 20-year experience with liver transplantation for polycystic liver disease: Does previous palliative surgical intervention affect outcomes? J Am Coll Surg 219: 695-703, 2014.

37. Temmerman F, Missiaen L, Bammens B, Laleman W, Cassiman D, Verslype C, van Pelt J and Nevens F: Systematic review: The pathophysiology and management of polycystic liver disease. Aliment Pharmacol Ther 34: 702-713, 2011.

38. Eason JD, Gonwa TA, Davis CL, Sung RS, Gerber D and Bloom RD: Proceedings of consensus conference on simultaneous liver kidney transplantation (SLK). Am J Transplant 8: 2243-2251, 2008.

39. Coquillard C, Berger J, Daily M, Shah M, Mei X, Marti F and Gedaly R: Combined liver-kidney transplantation for polycystic liver and kidney disease: Analysis from the United Network for Organ Sharing dataset. Liver Int 36: 1018-1025, 2016.

40. Kwok MK and Lewin KJ: Massive hepatomegaly in adult polycystic liver disease. Am J Surg Pathol 12: 321-324, 1988.

41. Starzl TE, Reyes J, Tzakis A, Mieles L, Todo S and Gordon R: Liver transplantation for polycystic liver disease. Arch Surg 125: 575-577, 1990.

42. Gedaly R, Guidry P, Davenport D, Daily M, Ronsenau J, Shah M, Cooper MA and Hundley J: Peri-operative challenges and long-term outcomes in liver transplantation for polycystic liver disease. HPB (Oxford) 15: 302-306, 2013.

43. Zamora-Valdés D, Contreras AG and Mercado MA: Liver transplantation for polycystic liver disease. J Am Coll Surg 219: 1192, 2014.

44. van Keimpema L, Nevens F, Adam R, Porte RJ, Fikatas P, Becker T, Kirkegaard P, Metselaar HJ, Drenth JP and European Liver and Intestine Transplant Association: Excellent survival after liver transplantation for isolated polycystic liver disease: An European Liver Transplant Registry study. Transpl Int 24: 1239-1245, 2011.

45. Arrazola L, Moonka D, Gish RG and Everson GT: Model for end-stage liver disease (MELD) exception for polycystic liver disease. Liver Transpl 12 (12 Suppl): S110-S111, 2006. 